\title{
Provocation to Reflect: An Educator's Exploration of Engaging Students Through Documentation
}

\author{
Ashley Frampton
}

\begin{abstract}
Ashley May Frampton holds a master's of education in interdisciplinary studies from the University of Calgary. She has been both a teacher and a learning leader with the Calgary Board of Education since 2009. Ashley has a bachelor in early childhood studies from Mount Saint Vincent University and a bachelor in elementary education from Acadia University. She is a member of the Calgary Reggio Network Association. Email: ashleymaypitts@gmail.com
\end{abstract}

This article is a personal narrative of how the author struggled to articulate her own philosophy of education while incorporating Reggio Emilia ideas into her teaching practice. The author found pedagogical documentation, an important component of the Reggio Emilia approach, to facilitate student self-assessment and intellectual engagement in Calgary schools. Her independent inquiry drew from her master's research, her reflections on her teaching philosophy, and her examination of the links between the Reggio approach and her school board's pedagogical goals. She identifies some challenges in using pedagogical documentation, and looks forward to future provocations that will deepen her understanding of what it means to be an educator.

Keywords: Reggio Emilia, pedagogical documentation, formative assessment, self-assessment, intellectual engagement

my practice. Specifically, it examines the connectivity I discovered between pedagogical documention, intellectual engagement. After providing some background into the question that sparked my interrogation of my teaching philosophy, as well as the links between that philosophy and the pedagogical goals of my teaching context, the Calgary Board of Education, I discuss the ways I have used pedagogical documentation in my practice and the opportunities it has provided for student self-assessment. Linking practice examples to literature on the Reggio approach, I also discuss the incorporation of these teaching strategies as a means to foster students' intellectual engagement. After touching on challenges and struggles I've faced along the way, I conclude by highlighting the value of self-reflection as a vehicle to deepen my understanding of what it means to be an educator.

\section{Background}

I was once challenged during a formal evaluation by a principal when he asked, What is your philosophy to teaching? This question caught me off guard, and I found myself pondering, self-critiquing, and questioning my practice. Why was it so difficult for me to articulate my teaching philosophy? Over the next year, I spent time reflecting on his question, attempting to encompass my knowledge, beliefs, and values into a philosophical framework. It was not until I began working with another principal who introduced the concept of Reggio Emilia at the elementary level that I was able to comfortably begin to form my own philosophical framework for teaching. Engaging families, the multiple languages of children, the environment, and project-based learning — many, if not all of the theories tied to Reggio Emilia aligned with my own personal beliefs as an educator.

In 2011, as a school team in a small, inner-city, Reggio-inspired school, my colleagues and I began focusing on the Reggio Emilia 
framework in many aspects of our practice, specifically on the documentation of learning - the process of making pedagogical work and learning visible and open to interpretation, dialogue, and transformation (Edwards, Gandini, \& Forman, 2011). Documenting students' learning and the ways they interacted with the documentation served as an important source of information for our whole team. Discussions and shared inquiry with teaching partners and school administrators were also crucial to this exploration. We were allocated time each week for collecting and analyzing student documentation, also taking time during professional development days to do group gallery walks of documentation panels to share our reflections, understandings, and next steps. These opportunities for collaboration and discussion were extremely beneficial as we developed our understanding of pedagogical documentation together and were provided with opportunities to self-reflect on our teaching practice, receive feedback from colleagues, and work together in fostering the continuous cycle of learning: What do our students know? What do we want them to know? What do they need to do next to get there?

As our school team worked with pedagogical documentation, I began to see a clear connection between the Reggio Emilia philosophy and the desired results of the Calgary Board of Education (CBE; 2016b) - academic achievement, personal development, character, and citizenship. My interest in the Reggio Emilia philosophy, and how it coincided with my role in Calgary schools, heightened as I became more experienced and comfortable as an elementary educator. I was constantly being reminded to consider the CBE results in my practice, all the while keeping in mind the board's mission that students come first and that our central purpose is learning (Calgary Board of Education, 2016b).

My curiosity continued to develop, and I found myself reviewing literature and reflecting on my own experiences working with children and colleagues, attempting to understand these values and outcomes in relation to the Reggio philosophy. Tracing back to the roots of Reggio and reading The Hundred Languages of Children (Edwards et al., 2011) allowed me to deepen my understanding of the Reggio Emilia philosophy and how it applied to my practice. Besides reading and thinking about documentation, I also looked at many peerreviewed articles on formative evaluation and intellectual engagement, which were major focuses within the CBE (Calgary Board of Education, 2016a). It became evident that pedagogical documentation aligned very closely with formative assessment, defined in the Alberta Student Assessment Study as the monitoring of students' daily progress to provide meaningful conversation and feedback about ways for students to hit defined targets and ways for the teacher to adjust teaching to meet students' needs based on evidence of students' progress (Weber, 2009). I understood the importance of this conversation and feedback in engaging students in their learning, and connections between pedagogical documentation, assessment, and intellectual engagement started to form. I found myself wondering, if this philosophy was used to successfully rebuild entire communities in Italy, couldn't we adapt it to transform schools for elementary students as well? Could we not use it to intellectually engage our students in learning and to foster academic and personal success for every student to carry forward after their time in school?

After several years of teaching in the Reggio-inspired school, in 2015 I accepted a position in a larger school without a Reggio focus. The decision to change schools was difficult, especially while I felt so deeply connected to the inquiry that was happening in my school. However, it was a time in my life when being closer to home and my family took precedence, and I also felt a responsibility to share my teaching team's great successes with educators and students outside of our small school. Having begun my personal inquiry into student self-assessment and intellectual engagement in a context where pedagogical documentation was a fundamental component of the school development plan, moving to a school where few teachers even understood the Reggio philosophy created some obstacles. I now had to make my research and philosophical understandings practical as a learning leader at my new school, where I was responsible for guiding a group of grade 4 teachers and engaging our small team in collaborative inquiry through our professional learning community. I began documenting students' learning and modelling what I felt was important to my teaching colleagues. Many were interested, intrigued, and even inspired, taking time to document and display glimpses of student learning themselves over our first few weeks together. Then, I found myself questioning and being questioned by others in the school. Why documentation? Where does it fit in the school development plan? In the CBE three-year plan? (Calgary Board of Education, 2016a). Is it worth the time and effort? I found myself struck by an unexpected level of discomfort and uncertainty, and was forced to continue asking ... why documentation? I searched for ways to inspire my teaching partners to understand the strong connection between pedagogical documentation and formative assessment and to use these approaches to support each other and grow as a team.

The concept of intellectual engagement was a key element of the CBE's three-year education plan (Calgary Board of Education, 2016a) and a focus of professional development at my new school. In fact, in all Calgary schools, focus has recently been placed on examining the relationship between student engagement and academic outcomes. The Canadian Education Association's initiative on student engagement, What Did You Do in School Today? examined over 60,000 middle and secondary students in Canadian schools. This study explored the concept of intellectual engagement, which they defined as an "absorbing, creatively energizing focus requiring contemplation, interpretation, meaning-making and critique" (Friesen, 2009, p. 4) that signifies a deep connection to and engagement with learning. The What Did You Do in School Today? teaching effectiveness framework and rubric (Friesen, 2009) was already being 
used by teachers in our school to evaluate their practice, specifically around creating tasks that intellectually engaged students. Working with my team, I wondered how I could connect pedagogical documentation to engagement, especially considering the three-year education plan that highlighted instructional design and leadership to foster student agency and intellectual engagement (Calgary Board of Education, 2016a). Did the process of documenting student learning engage students intellectually in their learning? I wanted to explore this question in my classroom.

\section{Pedagogical Documentation, Student Self-Assessment, and Intellectual Engagement}

Recently, my grade 4 students were engaged in a creative visual arts project in social studies. They were required to sculpt a representation of one of Alberta's natural regions, showing the unique landforms, climate, vegetation, animals, and natural resources found in the province. Through documentation collected by both students and teachers, it was evident that this project was much more than a beautiful art piece. Rather, it involved the integration of visual arts, research, inquiry, nonfiction writing, technology, and collaborative learning, to name a few.

The project was guided by student questions: Where does our water come from? Why are the lakes in Alberta the unique colour they are? How are all of the natural regions connected? Why do we have dinosaur fossils in Alberta? As shown in Figure 1, students' "I wonders," their use of co-created criteria, and the way they practiced mixing paint colours to match the photograph of the Canadian Shield came together in a documentation display that students used to self-reflect on their initial understanding of the Shield and to inquire into the unique population who lived there, specifically the First Nations people.

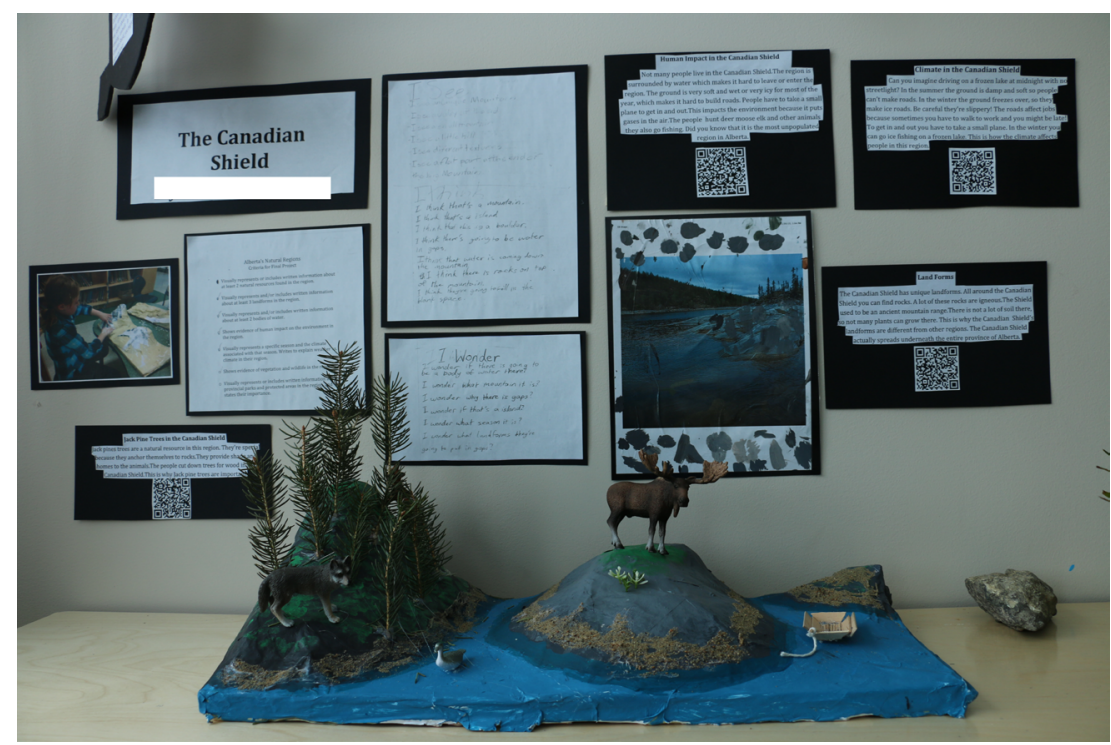

Figure 1. This documentation display, created with evidence gathered by both teacher and students in grade 4, shows process as well as final product.

The processes of observation and documentation highlighted in the example above are central to the Reggio Emilia philosophy, which focuses on paying more attention to how children learn than to specific curricular content. The Hundred Languages of Children (Edwards et al., 2011) calls this approach the pedagogy of listening; it outlines documentation as an important tool for assessment and a solution to the "proliferation of assessment and evaluation tools that have become ever more anonymous and decontextualized-objective and democratic in appearance only" (Edwards et al., 2011, p. 227). Wien (2011) defines documentation as the development of a learning story or pedagogical narration, and views it as a way for teachers to study learning in order to figure out what to teach. Documentation is a teaching practice that captures children's learning through the collection of evidence, such as transcripts, video, pictures, writing samples, and visual journals, and allows for the careful analysis of student learning processes and products. For example, in the visual arts and social studies project described above, the students' end product - a beautiful, accurate representation of their chosen regionwas obvious; however, the process of how each student got there would have been much less visible had there been no documentation. Without pedagogical documentation, the criteria, students' initial beliefs, questions, challenges throughout the process, cross-curricular learning experiences, and successes may have been overlooked. 
Beyond these definitions of documentation, strong pedagogical documentation involves sharing evidence of learning with students through displays and representations that provoke further reflection on learning experiences (Buldu, 2010), current levels of knowledge, and next steps. In my class's Canadian Shield project, the collection of evidence over the duration of the project allowed students to revisit and self-reflect on a learning process that took place over several months. I was able to guide their self-assessment by asking thought-provoking questions: What did we think we knew? What do we know now? What was challenging for you? Where do you need to go next? New projects and learning stemmed from these reflections and student interest, such as how to effectively take on roles in small groups, the exploration of Alberta settlers, and exploring in greater depth Alberta's unique fossil heritage.

As stated in The Hundred Languages of Children, the pedagogy of listening associated with documentation is closely related to formative assessment, "which is used throughout the educational experience to inform teaching and learning" (Edwards et al., 2011, p. 274). Black and Wiliam (1998) define formative assessment as a method that is used to adapt teaching to meet students' needs in order to develop an understanding of the meanings of the experiences of children, teachers, and parents. The Calgary Board of Education (2015) views formative assessment as involving the ongoing process of seeking and interpreting evidence that students and teachers will use to inform next steps in learning. In my teaching practice, I have found that pedagogical documentation encompasses these definitions by allowing students to revisit their experiences and products and self-reflect on their learning. The teacher's role is to scaffold student learning by asking questions that promote reflection, encouraging students to expand on ideas or share challenges throughout the process. Revisiting and thinking about the learning process in new ways is a tool for student self-assessment, an important goal of documentation (Fyfe, 2011).

In my experience, providing students with opportunities for self-assessment has yielded many benefits in their learning. For example, it allows students to become reflective, thoughtful, and active constructors of knowledge. In the project mentioned above, there were many opportunities for both self and peer reflection. Throughout the project, students often paired with other students or worked in small groups or with the entire class to carefully observe and reflect on each other's progress and engage in thinking routines (Project Zero, 2015) about the project with their peers (see Figure 2). These routines often included a simple, structured set of questions that were used to promote thinking (Project Zero, 2015) about their projects. Examples of thinking routines included I see, I think, I wonder, and I used to think ... Now I think ... (Project Zero, 2015). These routines were beneficial because they allowed students to set goals for themselves, could be used repeatedly in the classroom, were simple to teach, and could be used by students in groups or individually to document thinking and learning (Project Zero, 2015). Students even began to use the terminology from the thinking routines independently when discussing their projects with peers. During one thinking routine, the class carefully observed the in-progress Canadian Shield project. Several students looked at the same formation on their visual representation, sharing three opposing observations. One said, "I see a small hill." Another shared, "I see an island." A third said, "I see a large mountain." The group was then challenged to alter their art - colour, texture, scale - to ensure that viewers knew they were looking at a large rock formation, which characterized the Canadian Shield. Students also then expanded their research, discovering that the Canadian Shield's rocky territory stems from the erosion and wear of mountains over millions of years.

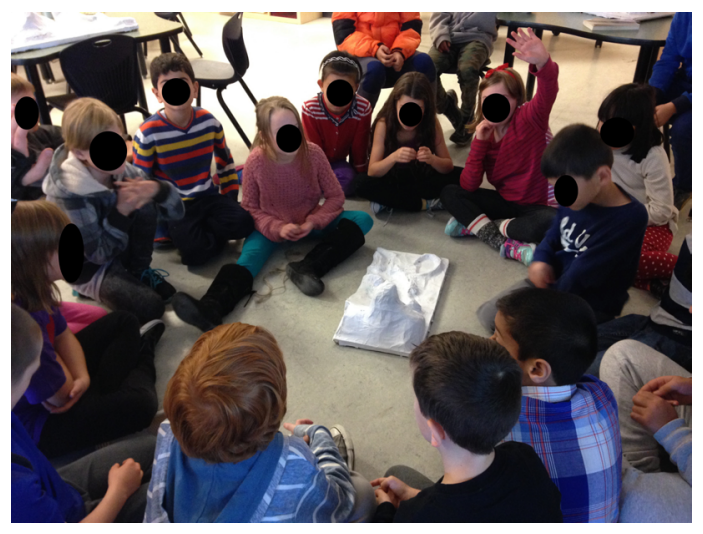

Figure 2. Students engaging in an I see, I think, I wonder thinking routine.

One of the biggest obstacles in implementing student self-assessment practices is that many teachers still take ownership of assessment in the classroom. This has been a challenge for me throughout my teaching career. Within the Reggio Emilia philosophy, a fundamental purpose of evaluation is to have students develop the ability to collaboratively evaluate themselves, and teachers must therefore release some of the responsibility for assessment to students, ensuring that when they graduate from school they are not reliant on others to tell 
them their level of achievement.

McMillan and Hearn (2008) state that self-assessment is the process through which students engage in monitoring and evaluating their thinking and behaviour during learning activities and identify strategies that will help them to improve their knowledge and skills. For example, in the project mentioned, students co-created criteria for their landforms with the teacher. These criteria were in the form of a checklist of components that needed to be evident in the final project. On this list, for example, was visual representation or written information on two bodies of water and shows evidence of human impact on the environment. Students were able to revisit the criteria throughout the project and ensure they were on track with their research and model. This was one way self-monitoring was made possible during the project.

From my perspective as a teacher, the documentation process, display, and student interaction with the documentation provide constant information about student learning. A focus on pedagogical documentation requires me to be teacher, researcher, and observer, rather than just a marker. This allows me to study deeply the ways students interact, question, inquire, and achieve learning goals in the classroom, while providing a more complete picture of the student in a variety of areas of development, such as social, language, and emotional. It also forces me as an educator to self-reflect on the learning process, on what I hoped students would learn, on what they actually learned, and on next steps. It provides a continuous cycle of assessment information on groups of students and individual students that can be used to guide further teaching and learning. As a teacher who has transitioned to using pedagogical documentation in my daily practice, I have witnessed students who demonstrate increased engagement in the learning process. Students are excited to see their learning journey documented with images of themselves, and they show pride in having their comments, questions, and artefacts displayed. The documentation also acts as a catalyst for deeper discussion and wonderings about their learning, creating an atmosphere where students are truly connected to projects and overall are more engaged in learning.

Intellectual engagement is different from academic engagement in that it involves "an absorbing, creatively energized focus resulting in a deep personal commitment to exploration, investigation, problem solving, and inquiry, maintained over a sustained period of time" (Jacobsen, Lock, \& Friesen, 2013, p. 14). Consider a grade 4 classroom. Students may be sitting quietly at their desks, using tools such as dictionaries and textbooks to support their learning and writing vigorously on a worksheet that asks them to define components of light and shadow. You might say this group of students is academically engaged in their work. However, it is unlikely that students are intellectually engaged in this task. In most cases, a worksheet does not ask students to create, explore, investigate, problem solve, or inquire over a sustained period of time, as an intellectually engaging task might ask them to do. Now walk into the same classroom on a different day. This time, students are working individually, collaborating in small groups, or conferencing with the teacher. They are using tools for research such as laptops, iPads, and nonfiction texts, as well as toying with components of light and shadow using flashlights, a variety of opaque, transparent, and translucent objects, and a retro overhead projector for shadow play. Some students are writing and editing stories, while others are designing props for a light and shadow play they are required to turn their stories into. This project will be presented to the larger audience of the school in just a few weeks. It is likely that many of the students in this scenario are intellectually engaged - deeply connected to and focused on their learning and engaged in creativity, problem solving, and inquiry.

\section{Struggles and Challenges}

I have experienced several challenges when using pedagogical documentation as a means of intellectually engaging students. One huge challenge is finding time and opportunity to create documentation panels and engage in conversations and reflections pertaining to students' learning artefacts with other teachers. As noted in a review by Project Zero (2003) at Harvard University, true documentation must be a process that includes a specific question and collective analyzing, interpreting, and evaluating observations; it must use different ways of expressing and representing, make learning visible, be shared with stakeholders, and shape the design of future contexts for learning. This requires a vast amount of teacher time and focus. Firlik (1996) shares that in order for North American cultures to adapt the documentation practices of Reggio Emilia, teachers must be given an abundance of planning time - up to six hours a week. Unfortunately, Canadian teachers receive on average only one hour of planning time each week, and although I have been fortunate to receive two hours a week most years, it is still not enough. I often found myself staying extra hours after school to analyze documentation and create panels. How can teachers find time to document learning? How can school leaders support this? Another consideration is the amount of effort that needs to be put into the display of aesthetically pleasing, time-consuming documentation panels. Do the final panels have the biggest impact on student learning? Does documentation have to look a certain way in order for students to use it as a tool for self-reflecting?

Also, in order for pedagogical documentation to truly engage students, teachers must become curators of the classroom who "capture 
moments of learning for later reflection" (Ritchhart, 2015, p. 235). Often, in a school where leaders encourage or even require pedagogical documentation as part of teacher practice, teacher accountability may have a negative effect on teachers' understanding of documentation. For example, I sometimes witnessed teachers rushing to finish documentation panels in time for gallery walks, in which case the purpose was lost and the focus was on getting the job done, rather than on the process. When teachers document because they feel accountable to administrators, it often becomes an added task rather than a way of thinking and researching student learning. I believe it is critical for school leaders to create an environment where all stakeholders value and understand the importance of pedagogical documentation and its connectivity to student learning. From my own experiences, when teachers truly understand the deep connection between formative assessment and pedagogical documentation, it becomes a way to teach rather than an extra thing to do. Of course, documentation needs to be a collaborative process, supported by school leaders who believe in the approach and are willing to dedicate the time for collaboration and learning throughout the school week.

\section{Final Thoughts}

Through my master's research, personal self-reflection, and ongoing contemplation and restructuring of my practice, I have developed a deeper understanding of the way pedagogical documentation intellectually engages students in their learning. I have come to understand documentation more deeply as an important teaching and learning strategy that encourages students to monitor and direct their own learning through self-assessment opportunities. This self-assessment contributes in turn to students who are intellectually engaged in learning. Documentation is a powerful tool for formative assessment that promotes self-reflection and evaluation, encourages discourse about learning experiences, and opens the door to an emergent curriculum that encompasses diverse topics. Although my philosophy as an educator will undoubtedly continue to grow with my teaching career and will change as the world changes around me, I believe that the concept of pedagogical documentation will always be an important part of it, because I now better understand its connection to pedagogical goals in the larger context of the school system. I look forward to the next provocation, possibly an uncomfortable question from a co-worker, that forces me to once again question my philosophy and step outside of my comfort zone as an educator. I know that these provocations, highly valued within the Reggio Emilia philosophy, will only act as catalysts for further thoughts, discussion, interests, questions, and opportunities for creativity that will deepen my understanding of what it means to be an educator.

\section{References}

Black, P., \& Wiliam, D. (1998). Inside the black box. Phi Delta Kappa, October, 1-13.

Buldu, M. (2010). Making learning visible in kindergarten classrooms: Pedagogical documentation as a formative assessment technique. Teaching and Teacher Education, 26, 1439-1449.

Calgary Board of Education. (2014). Understand: Assessment and reporting. Retrieved from: http://schools.cbe.ab.ca/b393/pdfs/ Assessment_Reporting_Jan_27_2014.pdf

Calgary Board of Education. (2015). Assessment and reporting: Overview of assessment and reporting. Retrieved from: http://www.cbe. ab.ca/programs/curriculum/assessment-and-reporting/Pages/Overview.aspx

Calgary Board of Education. (2016a). Calgary Board of Education three year education plan 2016-19. Retrieved from: http://www.cbe. ab.ca/FormsManuals/Three-Year-Education-Plan.pdf

Calgary Board of Education. (2016b). Policies and regulations: Results policies. Retrieved from: http://www.cbe.ab.ca/about-us/policiesand-regulations/Pages/Results-Policies.aspx

Edwards, C. P., Gandini, L., \& Forman, G. (Eds.). (2011). The hundred languages of children: The Reggio Emilia experience in transformation ( $3^{\text {rd }}$ ed.). Santa Barbara, CA: Praeger.

Firlik, R. (1996). Can we adapt the philosophies and practices of Reggio Emilia, Italy, for use in American schools? Early Childhood Education Journal, 23(4), 217-220. doi: 10.1007/BF02353340

Friesen, S. (2009). What did you do in school today? Teaching effectiveness: A framework rubric. Toronto, ON: Canadian Education 
Association.

Fyfe, B. (2011).The relationship between documentation and assessment. In C. Edwards, L. Gandini, \& G. Forman (Eds.), The hundred languages of children: The Reggio Emilia experience in transformation ( $3^{\text {rd }}$ ed.; pp. 273-292). Santa Barbara, CA: Praeger.

Jacobsen, M., Lock, J., \& Friesen, S. (2013). Strategies for engagement. Education Canada, January, 14-18. Retrieved from: http:// www.cea-ace.ca/education-canada/article/strategies-engagement

McMillan, J. H., \& Hearn, J. (2008). Student self assessment: The key to stronger student motivation and higher achievement. Educational Horizons, 87(1), 40-49. ERIC No. EJ815370. Retrieved from: http://eric.ed.gov/?id=EJ815370

Project Zero. (2003). Making teaching visible: Documenting individual and group learning as professional development. Cambridge, MA: Harvard University.

Project Zero. (2015). Thinking routines. Retrieved from: http:/www.visiblethinkingpz.org/VisibleThinking_html_files/03_ ThinkingRoutines/03a_ThinkingRoutines.html

Ritchhart, R. (2015). Creating cultures of thinking: The eight forces we must master to truly transform our schools. San Francisco, CA: Jossey-Bass.

Weber, C. F. (2009). The Alberta Student Assessment Study final report. Retrieved from: https://archive.org/details/albertastudentas00webb

Wien, C. A. (2011). Learning to document in Reggio-inspired education. Early Childhood Research and Practice, 13, 2. Retrieved from: http://ecrp.uiuc.edu/v13n2/wien.html 